\title{
Training and Productivity of Job, Effectiveness of Stress Management on Stress Reduction Index, A Randomized Clinical Trial
}

\author{
Mahbobe Amirbeik $^{1 *}$, Samane Akbarnia ${ }^{2}$, Maryam Jalalifar ${ }^{3}$
}

\section{ABSTRACT}

Introduction: perhaps it was unlikely to imagine the outbreak of insufficient psychological sequences in a few decades ago. A new form of psychic sequences has appeared due to industrialism and market competition. The current study was used with the aim of analysis the effectiveness of stress management to the teachers stress. Methods: in a semi-experimental layout in format of random clinical trial, 163 teachers were selected according to the entrance and departure criterion, among all teachers during 91-92 academic year, primary school, Sheshtmand province. After screening, based on stress criterion, 40 subjects with highest rank were selected according to the assumption threshold of tow standard deviation lower than the average and randomly assigned, using EXCEL, in format of two groups; Examinees group and controlling group (each group consists of 20 subjects). Stress management protocol was submitted to the examinees group for 10 weekly sessions. Job stress (response 94\%) applied 2 times. The data was analyzed by Univariate Analysis of Covariance (ANCOVA). Results: results showed that teaching stress management has a significant impact on reducing the teachers stress criteria than control group $(\mathrm{p}<0.05)$. Conclusion: research results indicate the efficiency of stress management teaching on modifying the psychological index. These accomplishments can lead to a promising perspective in field of education, and planning prevention programs to increase the effectiveness of practical training.

Keywords: Stress Management, Primary School Teachers, Teaching Stress, Clinical Trial

\footnotetext{
${ }^{1}$ M.A in School Counseling, Department of School Counseling, Faculty of Humanities, Islamic Azad University, Quchan Branch, Quchan, Iran

${ }^{2}$ M.A in School Counseling, Department of School Counseling, Faculty of Humanities, Islamic Azad University, Quchan Branch, Quchan, Iran

${ }^{3}$ M.A in School Counseling, Department of School Counseling, Faculty of Humanities, Islamic Azad University, Quchan Branch, Quchan, Iran

*Responding Author

(C) 2016 M Amirbeik, S Akbarnia, M Jalalifar; licensee IJIP. This is an Open Access Research distributed under the terms of the Creative Commons Attribution License (http://creativecommons.org/licenses/by/2.0), which permits unrestricted use, distribution, and reproduction in any Medium, provided the original work is properly cited.
} 


\section{Training and Productivity of Job, Effectiveness of Stress Management on Stress Reduction Index, a Randomized Clinical Trial}

We are witnessing nowadays emerging phenomena which are the result of growth of societies in format of modernity. Perhaps it was unlikely to imagine the outbreak of insufficient psychological sequences because of job performances, in a few decades ago. A new form of psychic consequences appeared due to industrialism and market competition.

Stress and psychological distress have drowned researchers' attention as the index of damaging and reducing job performances. Employment is considered as a factor of stressful situation. Stress is a common phenomenon in teaching field and they have reported an amount of stress in different grades and different periods. (Caballero, 2009).

Job stress has great impact on job efficiency as mediator index in format of hidden component. Job stress contains annoying emotional responses in format of disproportion between demands and job requirements toward talents or staff resources (Vafaii, 2001). Job stress can reflect in efficiency reduction, motivations and talents, besides, large amount of that can lead employees to quit their job. Job stress can be the reason of anxiety disorders. Here, role of stress in expressing mood disorders is considered (Mahboub, 2011). Also personal experiments of facing inconsistent, conflict-provoking demands, lack of information or failure of duties are causes of job stress (Duraisingam, 2009). According to the researches in different countries, teaching is one of the stressful professions in the world, and one third of the teachers believe that teaching is truly stressful. Stress can decrease teaching qualities in two ways; first, if the teacher finds it hard to teach for a long term, it may reduce their satisfaction to continue their job and discourages them. Second, stress may probably decrease the quality of the standards in the classroom (Kyriacou, 2001).

Teachers stress can have several contexts. Stressful reasons like teaching unmotivated students, lack of time, difficulty of controlling bad-behavior students, difficulty of interoperability with parents and failure of motivation (Antoniou et al, 2006), difficulties related to the classroom structure, classroom disharmony (Forlin, 2001), atmosphere of an irresponsible formation, and failure to understand the problems from authorities of the training organization. The above mentioned can appear as physical symptoms like headache, ulcer, chronic pain, nervousness, low efficient feelings and depression in the teachers. Although, the cognitive beliefs of teachers are really effective. Teachers with insufficient beliefs are less tolerated and more vulnerable to face the stress (Jesus and Conboy, 2001).

From the point of view of educational nature, the issue of stress management training is not to encourage subjects to omit stress from their life. As Sile motions, life would be exhausting and boring without challenges and stressful situations. Accordingly, the aim of stress management is to aware of the nature and effectiveness of stress, and guide them to benefit from the 
intrapersonal and interpersonal skills (Mikinam, 1997). Sile has entitled the individual efforts of controlling the demands beyond the resources as Opposition.

Stress management methods are codified with the aim of teaching subjects hoe to prevent, reduce, cope with, and adopting the stress (Kyriacou, 2001). Regarding, teachers stress can negatively affect the level of adjustment and students learning as an environmental factor. Teachers stress seeks low efficiency of classroom management, less students' involvement, and student negative emotions (Chan, 2002).

As stated, interfering on teachers level, and the attempt of decreasing their stress, thereupon, increasing the learning amount of the group work, and improving the environment of learning, is some of the difficulties in framework of education (Asgharnezhad, 2005). According the above discussion, and concerning teachers mental health as an influencing population in the process of training the new generations, we analyze the influence of stress management training to reduce the teachers stress.

\section{METHODS}

The current research is semi-experimental and performed in the format of a Randomized Clinical Trial. The statistical population is consists of all teachers (male, female) employed in primary schools in Sheshtmand province, during academic year 1391-92, containing 163 subjects (73 male, 90 female). The mentioned population was screened to distinguish the anxious subjects. 40 subjects with the highest rank were selected according 2 lower average standard deviations from the expectation value, and assigned randomly in two groups of examinees and controlling groups (each containing 20 examinees). The criterion of the research consists of age range of 25 to 55, and graduated subjects with at least higher diploma. Stress management training protocol offered to group of examinees for 10 weekly sessions. The examinees of controlling group were placed in waiting list. Job stress questionnaire fulfilled in pre-test and post-test. In order to incorporate the moral principles, examinees of the controlling group were offered 5 weekly sessions of stress management group work.

\section{Ethical Principles}

In this study, the informed consent was obtained without coercion, threat, enticement and seduction and their decision to refuse or accept to participate in the study were respected. It was also tried that the research methods do not contradict with the religious and cultural principles of the participants and the participants were respected in all stages of design, implementation and reporting in terms of human dignity, respect and protection of their physical and mental integrity. 
Training and Productivity of Job, Effectiveness of Stress Management on Stress Reduction Index, a Randomized Clinical Trial

\section{Research Instruments}

Job stress questionnaire (HSE): the questionnaire is prepared to examine the stress related to the job. The questionnaire has been evaluated by different methods. After reviewing the content, in order to review the structure, the following applied simultaneously and in sequence: survey explanatory and confirmatory factors, Pearson correlation coefficient, Cronbach's alpha. SPSS 15 and Amos 16 used to analyze the data. Accomplishments are as follow: the GHO and HSE correlation coefficient is $\mathrm{r}=0.48$, Also the results indicate an strong correlation between the extracted factors of factor analysis and HSE questionnaire items. Range of role, relation, support of authorities, support of partners, monitoring, demands, variations are in sequence $(0.92,0.73$, $0.75,0.63,0.87,0.85,0.22)$. The questionnaire reliability was 0.78 and 0.65 , applying Cronbach's alpha and half split methods. The HSE questionnaire is valid to analyze the job stress (Marzabadi, 2009).

\section{RESULTS}

According the research layout, the interfering clinical, using pre-test and post-test, and existence of job stress dependent variable of interval scale, applied to analyze Univariate Analysis of Covariance (ANCOVA). Also, the assumptions of the test like normal distribution and equality of variance, authenticated before analysis.

\section{Normal distribution of variance}

In order to survey the normality of the variables, KS (Kolmogorov Smirnov) applied. According to the results, it is deducted that job stress distribution of variance is normal ( $\mathrm{p}>0.127)$.

\section{Mean and standard deviation of the research variable}

The Mean and standard deviation during pre-test and post-test are in the Table

Table 1: Mean and standard deviation of Stress

\begin{tabular}{|l|l|l|l|}
\hline Index & group & process & Mean and SD \\
\hline & EXP & pre-test & $10.51(1.74)$ \\
\hline Stress & & post-test & $9.83(1.42)^{*}$ \\
\hline & Control & pre-test & $10.22(1.95)$ \\
\hline & & post-test & $11.13(1.22)$ \\
\hline
\end{tabular}

As you see, there is a significant difference of stress index between numbers of pre-test and posttest of stress index in experimental group.

\section{Equality of Variances}

One of the preconditions to apply the covariance statistical analysis is non-significance of Levene static about examines index, Results are in table 2: 
Training and Productivity of Job, Effectiveness of Stress Management on Stress Reduction Index, a Randomized Clinical Trial

Table 2: Levene Test for Equality of Variances

\begin{tabular}{|l|l|l|}
\hline group & Leven & significance \\
\hline EXP & 0.614 & 0.215 \\
\hline Control & 0.429 & 0.273 \\
\hline
\end{tabular}

According to table 2, computing the Levene statistic, to analyze the Equality of Variances, conveys the insignificant of the index.

Univariate Analysis of Covariance (ANCOVA)

In the table 3 Univariate Analysis of Covariance four stress variance is proposed.

Table 3: Univariate Analysis of Covariance for stress

\begin{tabular}{|l|l|l|l|l|l|l|}
\hline Index & SS & df & MS & F & p-value & Eta \\
\hline Stress & 2227.80 & 1 & 2227.80 & 14.64 & 0.05 & 0.58 \\
\hline
\end{tabular}

As mentioned, dependent variable has a meaningful effect on stress variable. $(\mathrm{p}<0.05)$

\section{DISCUSSION AND CONCLUSION}

The aim of the current study issues evaluating the efficiency of stress management on employed teachers' index. The accomplishments show that teachers in training courses (examinees group) have lower stress than the teachers in the controlling group, in post-test training. In this regard and parallel to the research accomplishments, former researches (Kyriacou, 2001; Dunham and Varma, 1998) indicated that holding training courses, despite of the favor of stress management to lower the amount of teachers job stress, sources and psychological signs were effected and leaded to improve the efficiency. Research accomplishments approve the studies. Although. The study is merely valid for the proper training courses to proper jobs. The training courses should be proportionated to the jobs. Generally, trainees are trained how to control their emotions and anxiety, and also are trained how to relax, so that they become able to cope with the hardships. Results of the research showed that the training courses were efficient to decrease the stress of employees (teachers). Conclusion of the current research is paralleled to the former research accomplishments (Mahboub, 2011; Taheri et al, 2006). On the other hand some aspects of the stress can cause more desirable efficiency. Without any stress it would be boring for the employees. Enforcing stressful situations improves the efficiency, and employees are ready to cope with the challenges mentally and psychologically. Extreme the optimal level increases the demand of abilities and the efficiency decreases. The current study is aimed to analyze the effectiveness of the training courses on the index of teachers stress. Accomplishments conveyed that the mentioned training course led to modification of the stress amount of the samples. These accomplishments can be useful to plan trial programs in the field of education. 
Training and Productivity of Job, Effectiveness of Stress Management on Stress Reduction Index, a Randomized Clinical Trial

\section{Acknowledgments}

The author appreciates all who supported and facilitated the process of the research.

\section{Conflict of Interests}

The author declared no conflict of interests.

\section{REFERENCES}

Antoniou, A.-S; Polychroni, F. \& Vlachakis, A.-N. (2006). Gender and age differences in occupational stress and professional burnout between primary.

Asgharnezhad, F., Salarifar, A. (2005). Analysis of teachers mental health and methods to improve and amend their mental health, research project, institute of education studies.

Caballero, M. (2009). A program designed for teacher in inclusion classrooms. Unpublished Ph. D. Dissertation, Carlos Albizu University Miami, Florida.

Chan. D. W. (2002). Stress, Self-Efficacy, Social Support, and Psychological Distress Among Prospective Chinese Teachers in Hong Kong. Educational Psychology.

Dunham, J. \& Varma,V(eds).(1998). Managing Work-related Stress: A Guide for Managers and Teachers in the schools.(2nd Edition). London: HMSO.

Duraisingam ,V \& Pidd, K \& Roch, A. M (2009) The impact of work stress and job satisfaction on turnover intevtions : A study of Australian specialist alcohol and other drog workers Drugs, education,prevention and policy. V:1

Forlin, C. (2001). Inclusion: identifying potential stressors for regular class teachers. Educational Research

Jesus, S.N. \& Conboy, J. (2001), A stress management course to prevent teacher distress. The International Journal of Educational Management.

Kyriacou, C. (2001). Teacher stress: Direction for future research. Educational Review.

Mahboub, F. (2011). Analysis of the stress management training on secondary deputies general health, Mashhad. Masters thesis, Azad University of Ghouchan.

Mikignam, D. (1996). Safety in taking stress training, Tehran, Roshd publisher.

Taheri, M., Mohebzadegan, Y., Zamanpour, E. (1386). The effectiveness of stress management training courses on the efficient beliefs of teachers. Research project. Shahid Beheshti University, Tehran.

Vafaii, M. (2001). Teachers' job stress, sources, job stress consequences among primary and high school, psychological researches.

How to cite this article: M Amirbeik, S Akbarnia, M Jalalifar (2016), Training and Productivity of Job, Effectiveness of Stress Management on Stress Reduction Index, a Randomized Clinical Trial, International Journal of Indian Psychology, Volume 3, Issue 4, No. 75, ISSN:2348-5396 (e), ISSN:2349-3429 (p), DIP:18.01.043/20160304, ISBN:978-1-365-50727-4 